\title{
«ТОБОЛЬСКИЙ МЫСЛИТЕЛЬ»: К ВОПРОСУ ИНТЕРПРЕТАЦИИ ОДНОГО ИЗ АНТРОПОМОРФНЫХ СЮЖЕТОВ ЭПОХИ ПАЛЕОМЕТАЛЛА ЦЕНТРАЛЬНОЙ АЗИИ
}

\author{
(С) 2020 г. И. Н. Швец
}

В статье анализируется антропоморфный персонаж, имеющий место в произведениях мелкой пластики и наскальном искусстве Центральной Азии, получивший условное название «Тобольский мыслитель». Автор привлекает новые аналогии данному сюжету в искусстве Средней Азии и Переднего Востока эпохи энеолита и ранней бронзы, а также обращается к вопросу этнокультурной и исторической интерпретации. Изображение людей в сидящей позе характерно для энеолитической антропоморфной пластики южных регионов Средней Азии и Переднего Востока. Широкий ареал данного образа показывает неоднозначность его семантики. Очевидно смысловое/семантическое многообразие сидящих антропоморфных фигур в искусстве палеометалла Центральной Азии. Природная естественность позы сидящего человека, компактность изображения сидящей фигуры, социальный (сижу - властвую) и профессиональный контекст данной позы предполагает различные трактовки данных артефактов и сюжетов, несмотря на их иконографическую близость.

Ключевые слова: археология, Центральная Азия, мелкая пластика, атропоморфный сюжет, петроглифы, окуневская культура, колесной транспорт, возничий, печати Урука

\section{Введение}

Сюжет сидящего с поджатыми кверху коленями человека принадлежит к одному из редчайших в искусстве палеометалла Централной Азии, нашедший свое воплощение не только в мелкой пластике, но и в наскальном искусстве. Подобные свидетельства сосуществования одного и того же образа в пластическом и изобразительном искусстве является большой редкостью в археологическом материале Центральной Азии эпох энеолита и бронзы.

Данная серия каменной антропоморфной пластики получила условное название «Тобольский мыслитель» в честь одной из первых скульптурок подобного типа, найденной близ г. Кустанай (современ- ное написание города - Костанай) (рис. 1, 3). Тобольская скульптурка человека, выполненная из песчаника, объединяет в себе наиболее характерные черты всех фигур этого типа - человек изображен сидя, большая голова выдвинута как бы вперед и немного вниз, фиксируется полное отсутствие шеи, руки согнуты в локтях и направлены параллельно вперед (рис. 1, 3-7, 10). Одна из казахстанских фигурок частично сохранила следы красной краски, т. е. была раскрашена в древности, вероятно, охрой [Новоженов, 2015, с. 314].

Коллекция каменных фигурок с поджатыми кверху коленями, найденная на территории Казахстана и Сибири, всегда вызывала интерес у исследователей и была довольно хо- 

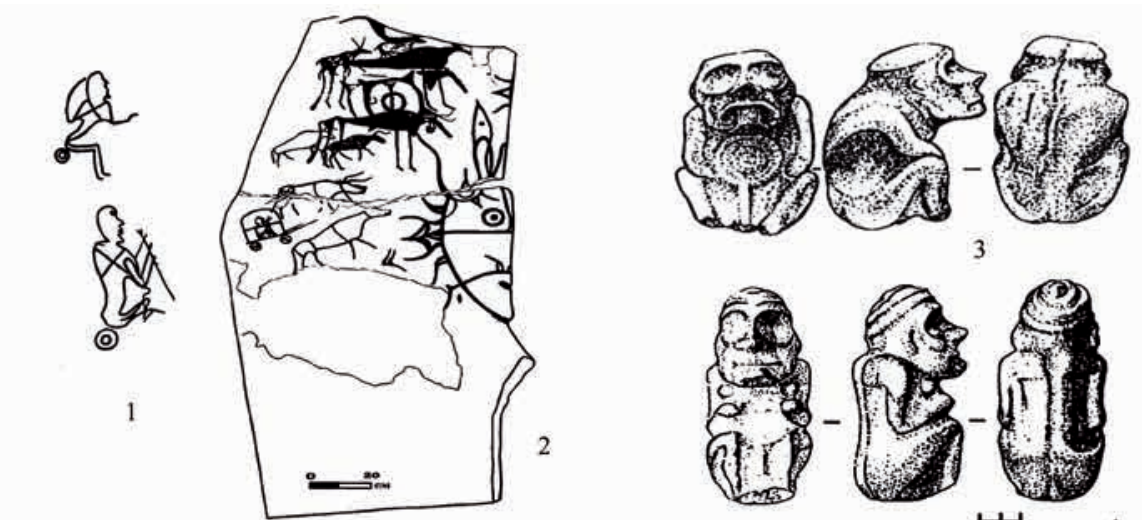

3
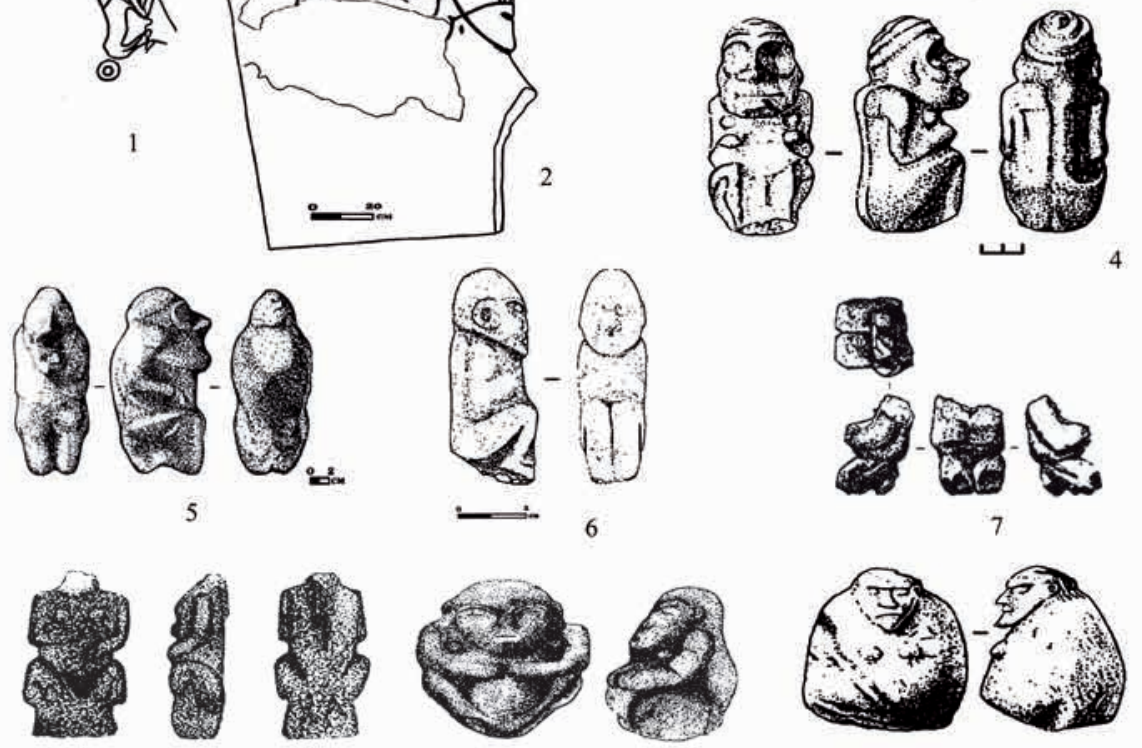

8

9

10

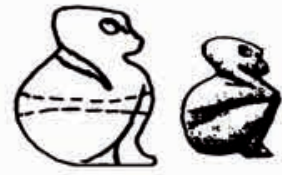

11

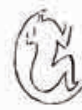

14

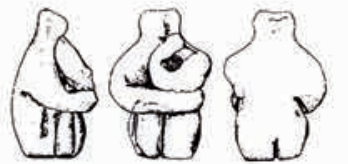

12

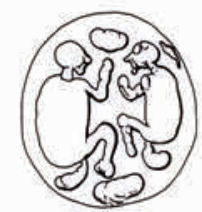

16

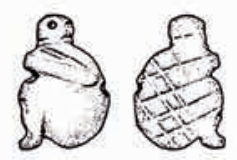

13

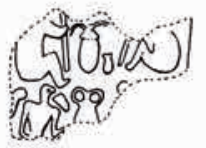

17

Рис. 1. Изображение антропоморфного персонажа в положении сидя:

1 - плита из мог. Черновая 8, Южная Сибирь; 2 - Знаменская стела, Южная Сибирь (по: [Новоженов, 2015, рис. 2]); 3 - 5-Северный Казахстан; 6-дер. Каль, Южная Сибирь; 7 - пос. Ботай, Северный Казахстан; 8-9-Хоутайци, Китай (nо: [Lie, 1996,

S. 38 Abb. 1]); 10 - к. Черновая 11, Южная Сибирь; 11 - печать, Фарухабад-Тэпэ, Иран (no [Rashad, 1990, Taf. 42, 1101]); 12 - пос. Драма, Болгария (nо: [Hansen, 2007, Taf. 338, 13]); 13-17- иилиндрические печати, Урук, Ирак (nо: [Boehmer, 1999, S.

115]). 1-7, 10- по: [Новоженов, 2015, рис. 1-2]

Fig. 1. Image of an anthropomorphic personage sitting: 1 - Chernovaya 8, South Siberia;

2 -Znamenskaya stela, South Siberia; 3-5 - Northern Kazakhstan; 6-Kaly, South Siberia;

7 - Botay, Northern Kazakhstan; 8-9-Houtaizi, China (by: [Lie, 1996]); 10 - Chernovaya 11, South Siberia; 11 - seal, Tepe Faruhabad, Iran (by: [Rashad, 1990]); 12 - Drama, Bulgaria (by: [Hansen, 20077); 13-17-cylinder seals, Uruk, Irak (by: [Boehmer, 1999]). 1-7, 10-by: [Novozhenov, 2015, Ill. 1-2] 
Швец И.Н. «Тобольский мыслитель»: к вопросу интерпретации одного из антропоморфных...

рошо описана и проиллюстрирована в публикациях О. П. Ченченковой [2004] и В. А. Новоженова [2015].

Характеристика и анализ материала

В передаче лиц данной серии фигур большое значение придавалось изображению большого носа и больших глаз. Кроме этого древний мастер стремился четко выделить ноги, согнутые в коленях, ступни и элементы одежды (рис. 1, 3-7, 10). Одна из каменных сидящих скульптур окуневской культуры из кургана Черновая XI, Южная Сибирь, интерпретируется как женская, так как на груди у фигуры имеются два выступа (рис. 1, 10). Все остальные детали данной фигуры свидетельствуют, по мнению В. А. Новоженова [2015, с. 314], в пользу ее мужского облика. Ю. И. Михайлов предполагает, что сидящая статуэтка из кургана Черновая XI, Южная Сибирь, является региональной иммитацией «to the more perfect Kazakhstan examples». Наличие данного образа в искусстве Окуневской культуры он объясняет юго-западными контактами населения Южной Сибии [Michajlov, 2001, c. 20].

3. Самашев и Г. Джумабекова, анализируя образ сидящей фигурки, найденной близ г. Костанай, характеризовали черты её лица - огромные, запавшие глаза, выделяющийся заостренный подбородок и нос - как черты умершего человека. По их мнению, коллекция мелкой пластики в виде сидящих фигурок представляет без исключения мужские образы [Samašev, Žumabekova, 1996, p. 237].

Возможность видеть в этой скульптуре женскую статуэтку все же не стоит отбрасывать, так как она обладает определенным сходством с чер- тами лиц так называемых костяных «куколок-божков» окуневской культуры из того же кургана Черновая XI, Южная Сибирь, женская идентификация которых однозначна [Вадецкая и др., 1980, табл. XXIV, 1-10].

Миниатюрные костяные и стеатитовые фигурки-головы, найденные в могильнике Черновая XI, Южная Сибирь, являющиеся «частями какихто мягких, меховых, кожаных или тряпичных кукол» [Вадецкая и др., 1980, c. 71], как и серия антропоморфных портативных «жезлов-изваяний», приведенная в работе В. А. Новоженова [2015, рис. 6], имеют определенное сходство с сидящими статуэтками - удлиненное лицо, выступающий вперед подбородок, плоская голова (головной убор?). Данные женские образы костяных «куколок-божков» окуневской культуры, как и антропоморфная серия сидящих фигурок, являются натуралистичными и не имеют никаких фантастических элементов. Этот факт представляет особый интерес, так как многие мотивы искусства окуневской культуры представлены в зашифрованном виде.

У второй минусинской фигурки, поврежденной еще в древности, отломлен нос (рис. 1, б). При этом фигурка в своих деталях полностью соответствует рассматриваемой нами серии - сидячая поза, массивная голова, отсутствие шеи, согнутые в локтях руки. Пожалуй, эта фигурка также уступает в качестве изготовления «to the more perfect Kazakhstan examples». Сидячая статуэтка из поселения Ботай, Северный Казахстан, сохранилась фрагментарно (рис. 1, 7), но по ряду признаков также может быть отнесена к рассматриваемой категории антропоморфной пластики. 
Наряду с портативными антропоморфными «жезлами-изваяниями» с территории Казахстана и Сибири и «куклами-божествами» из кургана Черновая XI, Южная Сибирь, еще одна необычная находка с поселения Саразм, Таджикистан, [Шкода, 1992; 1997] имеет иконографическую общность с рассматриваемой нами серией антропоморфной пластики. Речь идет о сосуде из порфирита с человеческой личиной [Новоженов, 2015, рис. 3], черты которой полностью повторяют черты лиц лучших казахстанских образцов сидящих фигурок.

Еще более редким является изображение сидящих антропоморфных фигур в петроглифах эпохи палеометалла. Большинство антропоморфных фигур в наскальном искусстве показаны стоя в полный рост. Иногда древним художникам удавалось передать определенную динамику в изображении человека. Это происходило путем сочетания двух манер изображения - профильной (торс) и в фас (ноги). Динамику антропоморфному персонажу придавал также контекст композиции и определенное положение рук и ног в изображении человека. Именно за счет этого были выделены в сюжетах наскального искусства такие персонажи как адоранты и танцующие.

На одном из обломков плиты окуневского могильника Черновая VIII, Южная Сибирь, были открыты схематичные рисунки двух сидящих людей. Головы и ноги антропоморфных даны в профиль, туловище - в фас, без шеи, с поднятыми кверху коленями [Вадецкая и др., 1980, с. 69]. Э. Б. Вадецкая отметила важную особенность, что «в аналогичных позах, как бы поджав коле- ни, сидят также окуневские хищники на писаницах и на плите тагарского могильника Черновая IX. Сама поза хищников, ее полное соответствие с позой человечков Черновой VIII свидетельствуют, что перед нами не звери, а люди в звериных наголовниках» [Вадецкая и др., 1980, с. 69]. Кроме сидящей позы эти фигуры объединяет позиция рук, вытянутых вперед и вверх, и знак в виде креста на груди [Вадецкая и др., 1980, рис. 12, 3] (рис. 1, 1).

Иконография схематичных как бы сидящих фигур на одной из плит могильника Черновая VIII, Южная Сибирь, аналогична иконографии возничего на Знаменской стеле окуневской культуры [Leont'ev, Kapel'ko, 2002, tаб. 27, 74]. Возничий, управляющий фургоном, изображен сидя и в профиль, с вытянутыми вперед и вверх руками (рис. 1, 2).

Среди недавно открытых петроглифов Кулжабасы (Жетысу) имеется изображение повозки, запряженной быками. На платформе показаны двое сидящих возничих [Байпаков, Марьяшев, 2004]. Фигуры иображены в профиль, одна за другой, ноги согнуты в коленях, руки направлены вперед [Новоженов, 2015, рис. 2, 3].

Сходство в исполнении двух антропоморфных фигур в сидящей позе на плите окуневского могильника Черновая VIII, Южная Сибирь, возничего на Знаменской стеле окуневской культуры, а также двух возничих в петроглифах Кулжабасы с коллекцией каменных сидящих антропоморфных статуэток с территории Казахстана и Сибири, позволили ряду авторов сделать предположение, что данная серия каменных статуэток является фигурками возничих (подробнее см.: [Новоженов, 2015, с. 316]). 
Швец И.Н. «Тобольский мыслитель»: к вопросу интерпретации одного из антропоморфных...

Изображение людей в сидящей позе более характерно для энеолитической антропоморфной пластики южных регионов Центральной и Средней Азии. По мнению Е. В. Антоновой, 90\% всех фигурок человека периода Намазга II и Намазга III, найденных на памятниках Южного Туркменистана, изображены сидя. Женские статуэтки в сидящей позе она интерпретирует как изображение рожениц [Антонова, 1978, с. 7]. Доминирование данного типа скульптур она объясняет более «пассивным» земледельческим образом жизни [Антонова, 1978, с. 8]. Подобная поза женских статуэток могла иметь, по мнению исследователей, и прагматичный характер. Некоторые из этих фигурок были найдены в ритуальных нишах домов эпохи энеолита Южного Туркменистана. Компактная поза сидящих статуэток могла способствовать более удобному их размещению в ритуальных нишах. Большинство из них могли иметь какие-то дополнительные функции, для чего служили сквозные отверстия в головах многих фигур [Шишкин, 1981, с. 60].

Интерес к данному образу антропоморфной пластики и наскального искусства вызван, прежде всего, необычностью передачи позы человека и реалистичностью подачи изображения. Подобная манера характерна не только для территории Сибири, Казахстана и Средней Азии. Так, в провинции Хэбэй в Китае были найдены шесть женских каменных скульптур, датируемых V тыс. до н.э. [Lie, 1996, p. 38, fig. 1] (рис. 1, 8-9). Самая крупная из этих фигурок (34 см) изображает беременную женщину в положении сидя. У скульпту- ры выделен округлый живот и грудь (рис. 1, 9). В своей иконографии фигура напоминает казахстанские и южносибирские образцы.

Изображение человека сидя характерно не только для мелкой пластики Средней Азии эпохи энеолита, но и для Южной Европы. Так, среди многочисленных глиняных фигурок с энеолитического поселения Драма (Болгария) выделяется одна, получившая название «Мыслитель» (рис. 1, 12). Речь идет о фигурке человека, который изображен сидя, ноги плотно согнуты в коленях, одна рука охватывает колени, другая подпирает подбородок. Данная антропоморфная статуэтка датируется эпохой энеолита, Каранова VI (са. 4500-4000 до н.э.) [Hansen, 2007, c. 240 , табл. 338,13$]$.

М. Рашад публикует в работе, посвященной развитию печатей урукского периода на территории современного Ирана, две печати из мрамора (или амулеты в форме печати (?)), на которых изображен, по мнению автора, человек или обезьяна, сидящая на корточках и охватившая голову руками (рис. 1, 11) [Rashad, 1990, табл. 42, 1101; 34, 2]. Автор, к сожалению, не даёт более детального описания этих находок и датирует их Джемде́т-Наср периодом (31002900 гг. до н.э.). Фигура человека или обезьяны изображена в профиль и по своей иконографии очень близка сидящим антропоморфным фигуркам из Казахстана и Южной Сибири.

В книге Р. Бёмера приводятся ранние экзэмпляры цилиндрических печатей урукского периода, найденные при раскопках городища Урук, расположенного на юге сегодняшнего Ирака [Boehmer, 1999]. Многие из них сохранились только фрагментар- 
но. Среди них присутствуют образцы, на которых изображен человек сидя, с руками согнутыми в локте и направленными вперед и вверх (рис. 1, 13-17). Данные образцы цилиндрических печатей датируются серединой урукского периода (3800-3400 гг. до н.э.) [Boehmer, 1999, с. 115]. Фигуры людей изображены в профиль и иконографически очень близки профильным антропоморфным фигурам, иображенным сидя, на плите окуневского могильника Черновая VIII, Южная Сибирь, возничего на Знаменской стеле окуневской культуры, а также двух возничих в петроглифах Кулжабасы. Изображение людей в сидящей позе на цилиндрических печатях Урука наделены рядом деталей и показаны в различных сценах. Качество публикации находок и отсутствие сопутствующей к ним информации затрудняет делать какие-либо выводы по изображенным сюжетам на печатях.

\section{Заключение}

Подводя итог анализу представленного в статье материала, необходимо отметить популярность данного образа в искусстве эпохи палеометалла Центральной Азии, выполненного при помощи различных материалов - из камня, кости, глины, мрамора или же в виде выбитого рисунка на плите/скале. Данный сюжет представлен в искусстве этого времени как «целостно», так и по принципу pars pro toto - личина на сосуде с поселения Саразм (Таджикистан). Можно также предположить, что сидящие фигурки на плите из могильника Черновая VIII (Южная Сибирь) были еще не закончены.

Очевидно смысловое/семантическое многообразие сидящих ан32 тропоморфных фигур в искусстве палеометалла Центральной Азии. Природная данность позы сидящего человека, компактность изображения сидящей фигуры человека, социальный («воседающий») и профессиональный (возничий) контекст данной позы предполагает различные трактовки данных артефактов и сюжетов, несмотря на их иконографическую близость. В этом смысле неправильно было бы все антропоморфные фигуры, изображенные сидя, интерпретировать как возничих. Так, рассматриваемая нами коллекция мелкой пластики с территории Казахстана и Сибири имеет, на наш взгляд, больше общего с мелкой пластикой Средней и Передней Азии. Данные антропоморфные изображения в сидящей позе возможно интерпретировать как фигурки/куклы (?) - божество для ритуальных ниш.

Широкий ареал данного образа и появление его в различных смысловых контекстах не облегчает его анализ, но одновременно показывает неоднозначность его семантики. Предложенный материал демонстрирует функциональное многообразие данного сюжета как определенного изобразительного канона в эпоху палеометалла, который мог выступать как в роли фигуры возничего, «ряженного», беременной женщины, так и в роли печати-амулета, «куколкибожества», антропоморфного жезла или ритуального сосуда, т.е. выполнять функции оберега.

Хронологическая атрибуция предложенной к рассмотрению коллекции мелкой пластики и наскальных рисунков на территории Казахстана и Южной Сибири второй половиной III тыс. - рубежом III-II тыс. 
Швец И.Н. «Тобольский мыслитель»: к вопросу интерпретации одного из антропоморфных...

до н.э. аргументированно доказана в работе В. А. Новоженова [2015], с которой автор данной статьи полностью согласен. Наличие общих канонов в мире художественных образов эпохи палеометалла на огромной территории Казахстана и Южной Сибири, их иконографическое родство с сюжетами Передней Азии свидетельствует о наличии тесных экономических и культурных связей данных регионов, что повлияло на формирование общего визуального языка.

\section{ЛИТЕРАТУРА}

1. Антонова E.B. К вопросу о значении поз антропоморфных изображений дописьменной эпохи (Передняя и Средняя Азия) // Древность и средневековье народов Средней Азии (история и культура). М.: Наука, 1978. С. 5-16.

2. Байпаков К.М., Марьямев А.Н. Петроглифы в горах Кульжабасы. Алматы: Print-S, 2004. 22 с. 88 илл.

3. Boehmer R.M. Uruk. Früheste Siegelabrollungen // Ausgrabungen in Uruk-Warka. Endberichte; 24. Mainz: von Zabern. 1999. 104 S.

4. Вадеикая Э.Б., Леонтьев Н.В., Максименков Г.А. Памятники окуневской культуры. Л.: Наука, 1980. 147 с.

5. Leont'ev N.V., Kapel'ko V.F. Steinstelen der Okunev-Kultur. Archäologie in Eurasien 13. Mainz: von Zabern, 2002. $110 \mathrm{~S}$.

6. Lie Chen. Der Ahnenkult im alten China // Das alte China. Menschen und Götter im Reich der Mitte, 5000 v. Chr. - 220 n. Zürich: Kunsthaus, 1996. P. 34-42.

7. Mikhailov Y.I. Genre Subject in the Petroglyphs and Portable Art of the Okunevo Culture // Вестник САИПИ. 4, 2001. С. 18-20.

8. Новоженов B.A. К вопросу об этнокультурной интерпретации коллекции антропоморфной пластики из памятников Центральной Азии второй половины 3 тысячелетия до н.э. // Древний Тургай и Великая Степь: часть и целое. Сб. научн. ст., посвящ. 70-летнему юбилею В.Н. Логвина. Костанай; Алматы: Институт археологии им. А.Х. Маргулана, 2015. С. 314-331.

9. Rashad M. Die Entwicklung der vor- und frühgeschichtlichen Stempelsiegel im Iran: im Vergleich mit Mesopotamien, Syrien und Kleinasien - von ihren Anfängen bis zum Beginn des 3. Jahrtausends v. Chr. Berlin: Reimer, 1990. $303 \mathrm{s.}$

10. Samašev Z., Žumabekova G. Spätbronzezeitliche Waffen aus Kasachstan // Eurasia Antiqua. 1996. Bd. 2. S. 229-241.

11. Svend H. Bilder vom Menschen der Steinzeit. Archäologie in Eurasien; 20. Bd 2. Mainz: von Zabern, 2007. 532 s.

12. Ченченкова О.П. Каменная скульптура лесостепной Азии эпохи палеометалла III-I тыс. до н.э. Екатеринбург: Тезис, 2004. 336 с.

13. Шишкин И.Б. У стен великой Намазги. М.: Наука, 1981. 189 с.

14. Шкода В.Г. К вопросу о северных связях Саразма // Северная Евразия от древности до средневековья: тез. конф. к 90-летию М.П. Грязнова. СПб.: ГосЭрмитаж, 1992. T. 2. C. $57-59$.

15. Шкода В.Г. Две каменные скульптуры палеометалла // СГЭ. 1997. С. 48-51.

\section{Сведения об авторе:}

Швец Ирина Николаевна - кандидат исторических наук, доктор археологии Германии (Хайделберг), независимый исследователь, преподаватель археологии в школах для одаренных детей (Германия), основатель педагогического центра «Занимательная археология для детей» (Хайделберг, Германия); schwezi@mail.ru 


\section{«ТОБЫЛ ОЙШЫЛЫ»: ОРТАЛЫК АЗИЯ ПАЛЕОМЕТАЛ ДӘУІРІНІН АНТРОПОМОРФТЫҚ СЮЖЕТТЕРІНІН БІРІН ИНТЕРПРЕТАЦИЯЛАУ МӘСЕЛЕСІНЕ}

\section{И. Н. Швец}

Мақалада Орталық Азия ұсақ пластика мен жартас өнері шығармашылығында «Тобыл ойшылы» деген шартты атауға ие болған антропоморфтық кейіпкер талданады. Автор энеолит пен ерте қола дәуіріндегі Орталық Азия мен Алдыңғы Шығыс өнеріндегі осы бір сюжетке жаңа үйлестікте назар аударады, сондай-ақ этномәдени және тарихи интерпретация мәселесіне жүгінеді. Жүрелеп отырған адам сұлбасының кескіні Орталық Азия мен Алдыңғы Шығыстың оңтүстік аймақтарының энеолиттік антропоморфтық пластикаларына тән. Осы образдың кең таралуы оның мағынасының күрделілігін көрсетеді. Сірә, Орталық Азия палеометал өнеріндегі отырған антропоморфтық тұлғалардың мағыналық/семантикалық мағынасы сан алуан. Отырған адам сұлбасының табиғи жаратылысы, отырған сұлба кескінінің жинақылығы, берілген кейіптің әлеуметтік (отырмын - билеймін) және кәсіби мәнмәтіні, олардың иконографиялық жақындықтарына қарамастан, аталған артефактілер мен сюжеттердің әртүрлі түсіндірілуін болжамдайды.

Түйін сөздер: археология, Орталық Азия, ұсақ пластика, атропоморфтық сюжет, петроглифтер, окунев мәдениеті, дөңгелекті көлік, арбакеш, Урук мөрлері

\section{«TOBOLSKY THINKER»: ABOUT INTERPRETATION OF ONE ANTHROPOMORPHOUS PERSONAGE IN THE ART OF CENTRAL ASIA IN THE ENEOLITHIC AND BRONZE AGES}

\section{N. Shvets}

The article is devoted to the anthropomorphic personage of small plastic art and rock art of Central Asia, which received the provisional name "Tobolsky thinker". The author draws attention to new analogies of this anthropomorphous personage in the art of the Central and Middle East of the Eneolithic and Early Bronze Age, and also addresses the issue of ethnocultural and historical interpretation of this rare plot. The presentation of people in a sitting pose is typical of the eneolithic anthropomorphic plastics of the southern regions of Central Asia. The wide range of this image shows the ambiguity of its semantics. It is obvious that the purpose of sitting anthropomorphic figures in the art of the Eneolithic and Bronze Ages of Central Asia was varied. The naturality of the pose of a sitting person, the compactness of the image of a sitting figure, the hierarchical and professional context of this pose implies different interpretations of these artifacts despite their iconographic similarity.

Keywords: archaeology, Central Asia, Middle East, small sculptures, anthropomorphous figure, petroglyphs, Okunev-culture, wheel transport, charioteer, seals of Uruk

\section{REFERENCES}

1. Antonova, Ye. V. 1978. In Drevnost i srednevekoviye narodov Sredney Azii (istoriya $i$ kultura) (To the question of the significance of poses of anthropomorphic images of the preliterate era (Middle East and Central Asia)). Moscow: „Nauka“ Publ., 5-16 (in Russian).

2. Baipakov, K. M., Maryashev, A. N. 2004. Petroglify v gorakh Kulzhabasy (Petroglyphs in the Kulzhabasy mountains). Almaty: „Print-S“ Publ. (in Russian).

3. Boehmer, R. M. 1999. In Ausgrabungen in Uruk-Warka. Endberichte; 24. Mainz: von Zabern (in German).

4. Vadetskaya, E. B., Leontiyev, N. V., Maksimenkov, G. A. 1980. Pamyatniki okunevskoy kultury (Monuments of Okunev culture). Leningrad: „Nauka“ Publ. (in Russian). 
Швец И.Н. «Тобольский мыслитель»: к вопросу интерпретации одного из антропоморфных...

5. Leont'ev, N. V., Kapel'ko, V. F. 2002. Steinstelen der Okunev-Kultur. Archäologie in Eurasien 13. Mainz: von Zabern (in German).

6. Lie, Chen. 1996. In Das alte China. Menschen und Götter im Reich der Mitte, 5000 v. Chr. -220 n. Zürich: Kunsthaus, 34-42 (in German).

7. Mikhailov, Y. I. 2001. In Vestnik Sibirskoy assotsiatsii issledovateley pervobytnogo iskusstva (Bulleten of Siberian Association of Primitive Art Researchers), 4, 18-20 (in English).

8. Novozhenov, V. A. 2015. In Beisenov, A. Z. (Ed.). Drevniy Turgay i Velikaya Step: chast $i$ tseloye (Ancient Turgay and Great Speppe: part and whole). Kostanay; Almaty: A.Kh. Margulan Institute of Archeology, 314-331 (in Russian).

9. Rashad, M. 1990. Die Entwicklung der vor- und frühgeschichtlichen Stempelsiegel im Iran: im Vergleich mit Mesopotamien, Syrien und Kleinasien - von ihren Anfängen bis zum Beginn des 3. Jahrtausends v. Chr. Berlin: Reimer (in German). German).

10. Samašev, Z., Žumabekova, G. 1996. In Eurasia Antiqua, Bd. 2, 229-241 (in

11. Svend, H. 2007. Bilder vom Menschen der Steinzeit. Archäologie in Eurasien; 20. Bd 2. Mainz: von Zabern (in German).

12. Chenchenkova, O. P. 2004. Kamennaya skulptura lesostepnoy Azii epokhi paleometalla III-I tys. do n.e. (Stone sculpture of forest-steppe Asia of the Paleo-metal era of the III-I millennium BC). Yekaterinburg: „Tezis“ Publ. (in Russian).

13. Shishkin, I. B. 1981. U sten velikoy Namazgi (At the walls of the great Namazga). Moscow: „Nauka“ (in Russian).

14. Shkoda, V. G. 1992. In Piotrovskiy, Yu. Yu. (Ed.). Severnaya Yevraziya ot drevnosti do srednevekoviya (Eurasian Steppes of Antiquity and the Early Middle Ages), 2. Saint Petersburg: State Hermitazhe Museum, 57-59 (in Russian).

15. Shkoda, V. G. 1997. In Soobshcheniya GosErmitazha (Reports of State Hermitage), 48-51 (in Russian).

\section{About the Author:}

Shvets Irina N. Candidate of Historical Sciences (Kazakhstan), Dr. Phil. Germany (Heidelberg), Independent researcher, teacher of archeology at schools for gifted children (Germany), founder of the pedagogical center "Living archaeology for children", Heidelberg, Germany; schwezi@mail.ru

\footnotetext{
Мүдделер қақтығысы туралы ақпаратты ашу. Автор мүдделер қақтығысының жоқтығын мәлімдейді. / Раскрытие информации о конфликте интересов. Автор заявляет об отсутствии конфликта интересов. / Disclosure of conflict of interest information. The author claim no conflict of interest.

Мақала туралы ақпарат / Информация о статье / Information about the article. Редакцияға түсті / Поступила в редакцию / Entered the editorial office: 12.05.2020. Рецензенттер мақұлдаған / Одобрено рецензентами / Approved by reviewers: 21.05.2020. Жариялауға қабылданды / Принята к публикации / Accepted for publication: 31.05.2020.
} 